\title{
Discovery and quantification of anaerobic nitrogen metabolisms among oxygenated tropical Cuban stony corals
}

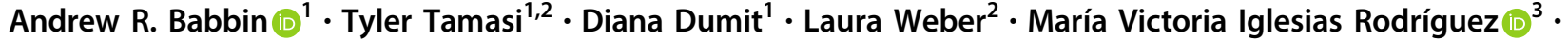 \\ Sarah L. Schwartz ${ }^{1,4} \cdot$ Maickel Armenteros $\mathbb{D}^{5,6} \cdot$ Scott D. Wankel $\mathbb{B}^{2} \cdot$ Amy Apprill ${ }^{2}$
}

Received: 17 July 2020 / Revised: 23 October 2020 / Accepted: 13 November 2020 / Published online: 20 December 2020

(c) The Author(s) 2020. This article is published with open access

\begin{abstract}
Coral reef health depends on an intricate relationship among the coral animal, photosynthetic algae, and a complex microbial community. The holobiont can impact the nutrient balance of their hosts amid an otherwise oligotrophic environment, including by cycling physiologically important nitrogen compounds. Here we use ${ }^{15} \mathrm{~N}$-tracer experiments to produce the first simultaneous measurements of ammonium oxidation, nitrate reduction, and nitrous oxide $\left(\mathrm{N}_{2} \mathrm{O}\right)$ production among five iconic species of reef-building corals (Acropora palmata, Diploria labyrinthiformis, Orbicella faveolata, Porites astreoides, and Porites porites) in the highly protected Jardines de la Reina reefs of Cuba. Nitrate reduction is present in most species, but ammonium oxidation is low potentially due to photoinhibition and assimilatory competition. Coral-associated rates of $\mathrm{N}_{2} \mathrm{O}$ production indicate a widespread potential for denitrification, especially among $D$. labyrinthiformis, at rates of $\sim 1 \mathrm{nmol}$ $\mathrm{cm}^{-2} \mathrm{~d}^{-1}$. In contrast, A. palmata displays minimal active nitrogen metabolism. Enhanced rates of nitrate reduction and $\mathrm{N}_{2} \mathrm{O}$ production are observed coincident with dark net respiration periods. Genomes of bacterial cultures isolated from multiple coral species confirm that microorganisms with the ability to respire nitrate anaerobically to either dinitrogen gas or ammonium exist within the holobiont. This confirmation of anaerobic nitrogen metabolisms by coral-associated microorganisms sheds new light on coral and reef productivity.
\end{abstract}

These authors contributed equally: Tyler Tamasi, Diana Dumit

Supplementary information The online version of this article (https:// doi.org/10.1038/s41396-020-00845-2) contains supplementary material, which is available to authorized users.

Andrew R. Babbin

babbin@mit.edu

1 Department of Earth, Atmospheric \& Planetary Sciences, Massachusetts Institute of Technology, Cambridge, MA 02139, USA

2 Department of Marine Chemistry and Geochemistry, Woods Hole Oceanographic Institution, Woods Hole, MA 02543, USA

3 Instituto de Ciencias del Mar de Cuba, Calle Loma No. 14 e/ 35 y 37, Alturas del Vedado, Plaza de la Revolución, La Habana 10600, Cuba

4 Program in Microbiology, Massachusetts Institute of Technology, Cambridge, MA 02139, USA

5 Universidad Nacional Autónoma de México, Instituto de Ciencias del Mar y Limnología, Ciudad de México, CDMX 04510, México

6 Universidad de La Habana, Centro de Investigaciones Marinas, 16 \# 114, Playa, La Habana 11300, Cuba

\section{Introduction}

Corals reefs are critical environments hosting diverse marine life despite a confined footprint within Earth's oceanic extent [1]. They thrive in shallow waters within a broadband from $30^{\circ} \mathrm{S}$ to $30^{\circ} \mathrm{N}$ of warm, sunlit, and relatively oligotrophic ocean waters [2]. Alarmingly, the success of coral reefs has floundered in recent decades in the face of increasing ocean temperatures, acidity, pathogens, and pressures from overfishing. These, along with other regional factors like anthropogenic nutrient runoff [3-5], have led to the degradation of $33-50 \%$ of the world's reefs, placing a quarter of all marine species at risk for extinction [6]. The health of the coral-algal partnership depends on a complex microbial community of bacterial, archaeal, fungal, and viral associates, collectively termed the coral holobiont [7]. This holobiont maintains a delicate nutrient balance in order to support life among a reefs' otherwise generally oligotrophic surroundings $[8,9]$. One such nutrient, fixed nitrogen, is essential for the production of amino and nucleic acids and is a principal limiter of ocean productivity. 


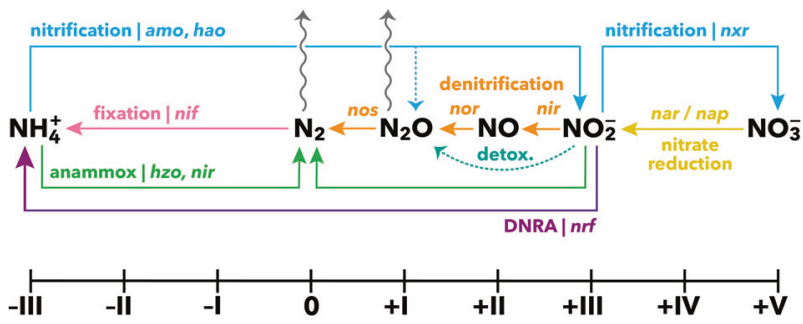

Fig. 1 Potential nitrogen cycle among coral organisms. The multiple inorganic nitrogen compounds are plotted according to the oxidation state of the nitrogen. The biologically mediated pathways are denoted by the functional gene responsible for each dissimilatory conversion. Notably, there are three major avenues for $\mathrm{N}_{2} \mathrm{O}$ production, all of which can lead to a flux from the surface ocean: nitrification (through decomposition of a hydroxylamine intermediate or via nitrifier denitrification), denitrification, and non-energy-yielding detoxification of nitrite.

Tropical reef-building corals flourish despite the apparent constraints of their nutrient-poor environments [10, 11]. Indeed, the standing concentration of fixed "bio-available" nitrogen within these regions (mostly as nitrate) tends to be $<1 \mu \mathrm{mol} \mathrm{L}{ }^{-1}$ (Supplementary Fig. 1). These organisms then are accustomed to life at the precipice of resource availability and are aided by diazotrophic microbial associates that can continually supply new nitrogen to the ecosystem [12-14]. The marine nitrogen cycle comprises a finely tuned set of chemical transformations executed by a diverse community of diazotrophic, nitrifying, and denitrifying microorganisms. Even though functional gene assays have identified these microbes in reef-building corals [15], direct evidence of their function within the overall ecosystem has not been fully explored. The nitrogen-fixing microbes responsible for the conversion of otherwise inert $\mathrm{N}_{2}$ to readily available ammonium $\left(\mathrm{NH}_{4}{ }^{+}\right)$, may allow corals to thrive despite low standing stocks of fixed nitrogen [16]; however, the roles of other nitrogen cycling pathways remain almost entirely unknown [17]. Given the importance of nitrogen to cell growth and its scarcity on reefs, the coralbased nitrogen cycle is likely to include the suite of processes observed in the global oceans and in other marine invertebrates [18].

Nitrogen is a globally important nutrient and proximal limit on marine photosynthesis across much of the oceans $[19,20]$. The overall budget of fixed nitrogen in the oceans is predominantly set by two main microbial pathways: nitrogen fixation as a source and denitrification as a sink [21]. Nitrogen fixation in the surface oceans, including tropical reefs, is largely attributed to autotrophic cyanobacteria [22]. Meanwhile, fixed nitrogen loss, has been generally considered limited to anoxic systems [23], including coral reef sediments [24]. A main contributor to this nitrogen loss is canonical denitrification, the sequential reductions of nitrate $\left(\mathrm{NO}_{3}{ }^{-}\right)$to nitrite $\left(\mathrm{NO}_{2}{ }^{-}\right)$to nitric oxide
(NO) to nitrous oxide $\left(\mathrm{N}_{2} \mathrm{O}\right)$ and finally to dinitrogen gas $\left(\mathrm{N}_{2}\right)$. The steps of denitrification are catalyzed by the enzymes nitrate reductase, nitrite reductase, nitric oxide reductase, and nitrous oxide reductase, encoded by the genes nar, nir, nor, and nos, respectively [25]. The enzymes that catalyze these nitrogen transformations display varying sensitivities towards oxygen [26], and so their activity can be dependent on local $\mathrm{O}_{2}$ microenvironments. Another energetically favorable nitrate reduction pathway, dissimilatory nitrate reduction to ammonium (DNRA), is encoded by the $n r f$ gene and is an anaerobic process that has been detected across diverse marine environments [27-29]. This dynamic cycle comprises many pathways distributed among different organisms, exchanging inorganic nitrogen metabolites through their dissimilatory metabolism (Fig. 1).

Broadly, the nitrogen cycle includes both aerobic and anaerobic pathways, with denitrification requiring low $\mathrm{O}_{2}$ $[30,31], \mathrm{N}_{2}$ fixation poisoned by the presence of $\mathrm{O}_{2}$ [32], but nitrification requiring $\mathrm{O}_{2}$ [33]. As a result, these processes are separated in space and time due to the inhibition of enzymes like nitrate reductase, the catalyst for the first step in denitrification, by oxygen [34, 35]. The diurnal variations in oxygen concentrations observed within the mucus films and tissues of corals may permit suboxic metabolisms in otherwise well-oxygenated bulk systems. Coral reefs exhibit dramatic diurnal fluctuations in dissolved oxygen [36], especially at the sub-millimeter scale within the gastric cavities and boundary tissue layers of individual corals, which can oscillate between full saturation in daylight to anoxia at night even as ambient water remains constant [37-39]. Indeed, mucus can act as an organic carbon source enabling rapid respiration [40] and as an oxygen retardation boundary to create localized anoxia [41]. Even though these low oxygen conditions prime reefs for nitrate reduction and denitrification, the ability of tropical reef microbial symbionts to conduct these processes has received less attention than reef carbonate sediments [24], oyster reefs [42], and tropical sponges [43].

There have been few direct rate measurements of fixed $\mathrm{N}$ loss despite the identification of microbial communities associated with nitrate reduction $[13,15,44]$. While suggestive, the molecular evidence highlights a need for direct rate measurements of denitrification in and isolation of coral individuals from tropical reefs in order to confirm the activity of suboxic metabolic pathways. Analogously, coldwater corals have been shown to exhibit a nitrogen cycle comprising fixation, nitrification, and denitrification [45-47]. Yet, these cold-water corals survive in deeper, darker, colder, and more nutrient-rich waters and are usually devoid of algal symbionts [48], making extrapolation of those results to the tropical surface tenuous. Tropical reef sponges harbor a markedly complex and tightly interwoven microbially-driven nitrogen cycle [43, 49], but sponges can 
actively modulate their internal oxygen concentrations to support both aerobic and anaerobic microbes [50]. In oligotrophic tropical reef environments, which neither conserve nor export significant quantities of inorganic nutrients [51], an active nitrogen cycle is vital for maintaining a highly productive system. The presence of denitrifying pathways in analogous organisms and characteristic oxygen fluctuations that can prime micro-zones for denitrification suggest a promising capacity of tropical corals to host anaerobic nitrogen metabolisms.

Here, in the well-preserved coral reef system Jardines de La Reina (Cuba) that generally harbors low standing stocks of dissolved inorganic nitrogen [52], we investigate the insitu cycling rates of inorganic nitrogen in five important Caribbean coral species using a multitracer experimental approach. We directly measure rates of nitrate reduction, ammonium oxidation, and nitrous oxide production from each possible inorganic nitrogen source via ${ }^{15} \mathrm{~N}$ tracer amendments. We hypothesize that nitrogen cycling variability is related to coral species. In addition, we isolated anaerobic nitrate-consuming bacteria in order to more fully understand the roles that denitrifying organisms have in governing coral reef dynamics and health.

\section{Materials and methods}

\section{Study site}

The Jardines de la Reina (Gardens of the Queen) is a relatively pristine Caribbean reef system located in the southeastern coast of Cuba, sheltered historically due to its remote nature from the Cuban coastline and protected officially since 1996 by the Cuban government. It hosts lower degrees of local pollution, fishing pressures, and other anthropogenic influences than are present in other areas of the Caribbean [53]. Many reef ecosystems elsewhere in the region, such as Jamaica and the Florida Keys, have been heavily impacted by these human influences and subsequent coral disease outbreaks $[54,55]$. The Jardines de la Reina stands in stark contrast, as an extensive National Park (a category of marine protected area) that has resulted in a well-preserved ecosystem. Additionally, the Jardines de la Reina maintains endangered coral species, like Acropora palmata, that have experienced precipitous population declines elsewhere in the Caribbean [56]. Fish and coral densities are highest in the central regions of the Jardines de la Reina and slightly lower at the northwestern- and southeastern-most parts, where fishing is permitted on a limited albeit regulated basis [57]. Sampling was conducted aboard the M/V Alucia in November 2017. Seven sites were chosen for sampling from a variety of reefs, and due to cruise and experimental logistical constraints, one coral

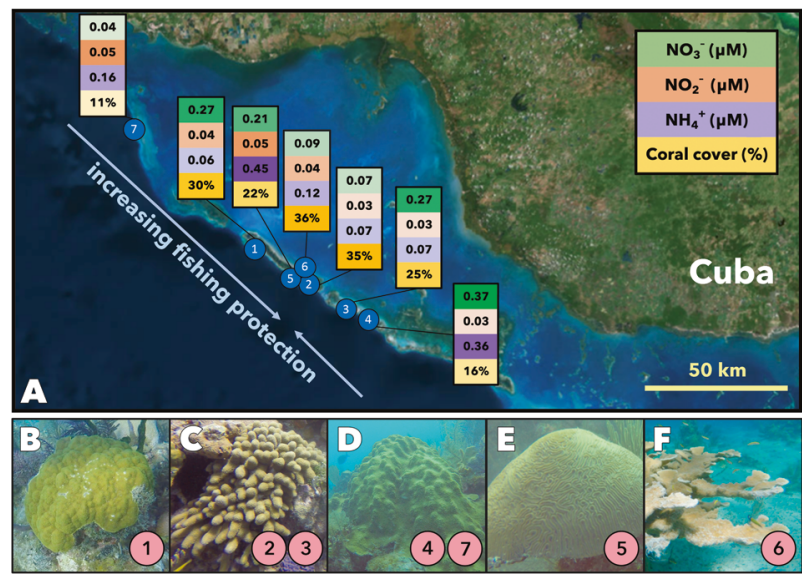

Fig. 2 Coral and reef water sampling in the Gardens of the Queen. A Locations of the seven sites that corals were sampled from for the incubation experiments. Shown are the measured inorganic nitrogen concentrations as well as the quantified coral coverage for the given section of reef, with higher and lower concentrations (or coverage) represented by the dark and light colors, respectively. Coral species sampled at each site (indicated in the pink encircled number): B Porites astreoides, C Porites porites, D Orbicella faveolata, E Diploria labyrinthiformis, and $\mathbf{F}$ Acropora palmata.

species was chosen per site based on prevalence and availability (Fig. 2). All of the sites sampled were forereefs (9-14 m), except A. palmata which was collected from a shallower $3 \mathrm{~m}$ reef.

\section{Reef metadata collection}

Samples for $\mathrm{NO}_{\mathrm{x}}^{-}$(as nitrate + nitrite), nitrite, and ammonium concentrations at each of the sites were collected at reef depth into clean $30 \mathrm{~mL}$ HDPE bottles and frozen at $-80^{\circ} \mathrm{C}$ until analysis (within 2 months) using standard colorimetric methods by Oregon State University [58, 59]. At each site, scuba divers conducted benthic surveys to estimate the percent coral cover relative to other reef substrates, such as macroalgae, sponges, rocks, and sand. The composition of each substrate (in $\mathrm{cm}$ ) was estimated along a transect tape at $1 \mathrm{~m}$ intervals for a total distance of $10 \mathrm{~m}$, and replicated 8-10 times for an individual reef site.

\section{Coral ${ }^{15} \mathrm{~N}$ incubation experiments}

Coral fragments for incubation were collected from a single colonial head per site by hammer and chisel. These fragments were maintained in WhirlPak bags and returned to the surface where they were kept at seawater temperature until introduction to the incubation vessels. Coral pieces were largely clean and lacking epiphytic and endolithic algae or sponges, confirmed by visual inspection after the experiments. Pieces ranged between 1 and $10 \mathrm{~cm}^{3}$ in volume, depending on the species sampled, and generally 
did not vary in size within an incubation by more than a factor of four. The corals sampled were: Porites astreoides (site 1), Porites porites (sites 2 and 3), Orbicella faveolata (sites 4 and 7), Diploria labyrinthiformis (site 5), and Acropora palmata (site 6).

The corals were transferred into sterile on-deck incubators within two hours of removal from the reef. Each vessel was a $12 \mathrm{~cm} \times 10 \mathrm{~cm} \times 3 \mathrm{~cm}(360 \mathrm{~mL})$ rigid, chemically inert, polycarbonate container selected for its relative clarity across the UV and visible light spectrum (Pelican Products, Torrance, CA) (Supplementary Fig. 2). This size chamber was selected to maximize the ability to detect ${ }^{15} \mathrm{~N}$ transformations happening in/on the coral fragment. The containers were modified to include a bulkhead compression port fitted with a gray chlorobutyl rubber septum and a Viton rubber gasket. The port allowed each container to be filled completely without residual air bubbles and also provided a means of injecting ${ }^{15} \mathrm{~N}$ tracers. Each customized container passed a 24-hour quality control test by not permitting the exchange of dye-injected water inside the container with bulk water outside. For each incubation, at least one coral piece was placed in a container that was then filled completely with reef water collected directly from the reef where the parent coral colony had been situated using a $10 \mathrm{~L}$ Niskin bottle. Using ambient reef water ensured that the chamber contained a similar chemical, microbiological, and metabolomic profile to the corals' natural environment and thus was more reflective of on-reef conditions. These chambers, filled with reef seawater and corals, were incubated at approximate reef temperatures maintained by supplying continuous flowing surface seawater to aquaria on the research vessel. In all, the time from the collection of corals on the reef to the start of the incubation via inoculation was approximately two to three hours.

After each container was sealed, each was amended to a

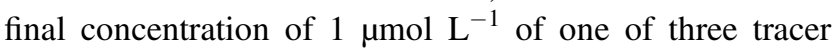
species: $\mathrm{K}^{15} \mathrm{NO}_{3}, \mathrm{Na}^{15} \mathrm{NO}_{2}$, or ${ }^{15} \mathrm{NH}_{4} \mathrm{Cl}$ (>99\%, Cambridge Isotope Laboratories, Tewksbury, MA). In addition, natural abundance additions of the complementary dissolved inorganic nitrogen (DIN) compounds were amended to serve as carriers and to standardize inoculation amendments across experiments. As such, $1 \mathrm{mmol} \mathrm{L}^{-1}$ stock solutions of the appropriate ${ }^{14 / 15} \mathrm{~N}$ compounds were mixed to make three combined tracer solutions: each contained one of three ${ }^{15} \mathrm{~N}$ labels and the two ${ }^{14} \mathrm{~N}$ carriers. Final concentrations were attained by a single injection of $1 \mathrm{~mL}$ of the combined tracer solutions into the incubation vessels via a $22 \mathrm{G}$ needle through the septum. The ${ }^{15} \mathrm{NO}_{3}{ }^{-}$tracer assessed rates of reduction to $\mathrm{NO}_{2}{ }^{-}, \mathrm{N}_{2} \mathrm{O}$, and $\mathrm{N}_{2}$ (denitrification), the ${ }^{15} \mathrm{NO}_{2}{ }^{-}$tracer tracked the rate of its reduction to $\mathrm{N}_{2} \mathrm{O}$ and $\mathrm{N}_{2}$, and the ${ }^{15} \mathrm{NH}_{4}{ }^{+}$tracer indicated the rates of oxidation to $\mathrm{NO}_{2}^{-}$(nitrification), $\mathrm{N}_{2} \mathrm{O}$ (nitrifier denitrification) and $\mathrm{N}_{2}$ (anammox). For each set of experiments, six incubations were performed per ${ }^{15} \mathrm{~N}$ label for a total of 18 individual incubations per site. Twelve of these contained corals from the designated site (four per ${ }^{15} \mathrm{~N}$ tracer), and an additional six incubations were seawater-only controls to measure ambient DIN cycling rates in reef water alone for comparison.

Incubations were separated into one of two different light treatments in order to investigate the impact of irradiance on DIN cycling rates. Half of the incubations (three per tracer) were covered with dark mesh to reduce incident light levels at the surface and better approximate ambient illumination at the coral's natural depth-this is referred to as the "ambient light" treatment-while the other was covered with opaque, black plastic in order to estimate the effect of lack of photosynthesis on the coral's biogeochemical nitrogen cycling profile, i.e., the "dark" treatment. Corals in the "ambient light" treatment were otherwise subject to the normal diurnal cycle. Light levels were confirmed using a photosynthetically active radiation sensor (Vernier, Beaverton, OR) and indicated that the mesh used in our "ambient light" treatment attenuated incident light by $80 \%$, thus approximating the light levels that corals would receive at a depth of 8-10 $\mathrm{m}[60,61]$.

At each site, seawater samples were also collected to serve as initial timepoints; one was collected for each ${ }^{15} \mathrm{~N}$ tracer experiment. Each was amended to a final concentration of $1 \mu \mathrm{mol} \mathrm{L}{ }^{-1} 15 \mathrm{NO}_{3}{ }^{-},{ }^{15} \mathrm{NO}_{2}{ }^{-}$or ${ }^{15} \mathrm{NH}_{4}{ }^{+}$and $1 \mu \mathrm{mol} \mathrm{L}{ }^{-1}$ of the complementary ${ }^{14} \mathrm{~N}$ species with the same isotopic tracer mixture injected into the experiments. This inoculated reef water was then immediately split between each of two sample bottles: a $30 \mathrm{~mL}$ acid-washed highdensity polyethylene (HDPE) bottle and a $30 \mathrm{~mL}$ glass serum bottle, both of which had been pre-aliquoted with $50 \mu \mathrm{L}$ of $50 \%$ (by weight) $\mathrm{ZnCl}_{2}$ as a preservative. $25 \mathrm{~mL}$ was injected into each bottle and the glass serum bottle was then crimped closed. This gastight sample was used for the isotopic measurement of dissolved $\mathrm{N}_{2} \mathrm{O}$ and $\mathrm{N}_{2}$, whereas the sample preserved in the HDPE bottle was used for the measurement of dissolved $\mathrm{NO}_{3}{ }^{-}$and $\mathrm{NO}_{2}{ }^{-}$.

Corals were incubated for a 24-hour period so as to capture a full diurnal cycle as well as to allow enough time for processing of the nitrogen inocula, but also provide a short enough window to minimize bottle effects typically associated with lengthy incubations. At the end of each incubation, the bulkhead cap was unscrewed and water samples were collected from each vessel. A total of $50 \mathrm{~mL}$ was split between the HDPE and glass serum bottles as in the collection of the initial timepoint samples. Once water samples had been taken, corals were removed from the vessels, wrapped in aluminum foil, and frozen at $-80{ }^{\circ} \mathrm{C}$ until processing. 


\section{Coral fragment surface areas and other physical attributes}

Estimated dry tissue weights, skeletal volumes, polyp counts, and active surface areas were determined for each coral sample. First, each coral piece was airbrushed (Paasche Model H, Chicago, IL) at 80 to 100 psi with 0.2 $\mu \mathrm{m}$ filter sterilized phosphate-buffered saline to remove coral mucus and tissue. The slurry was vortexed for $20 \mathrm{~min}$ to homogenize and a fraction of it was then dried and weighed. Cleaned coral skeletons were measured for surface area, skeletal volume, and polyp counts, all of which were more reliable than the dry weight estimates (Supplementary Table 1). Coral active surface areas were estimated by wrapping each cleaned coral skeleton in a monolayer of aluminum foil and weighing the resultant mold [62]. Foil was used to cover only the area of coral that would have had live tissue, and all measurements used a single roll of standardized foil. Although widely adopted, this protocol does not capture finer details of structure inside of polyps and on species with particularly complex polyp morphologies, like $O$. faveolata [63]. Polyp density was determined by individually counting every polyp on each coral piece via visual inspection and then normalizing by the surface area estimates. Coral volumes were measured by water displacement in 25 or $50 \mathrm{~mL}$ graduated cylinders, depending on coral fragment size.

\section{${ }^{15} \mathrm{~N}$ mass spectrometry}

The isotopic compositions of dissolved nitrogen species, ${ }^{15} \mathrm{~N} /{ }^{14} \mathrm{~N}$, were determined using a continuous flow IsoPrime 100 isotope ratio mass spectrometer (IRMS; Elementar Americas, Inc., NY). Ammonium oxidation to nitrite and nitrate reduction to nitrite samples were measured after quantitative conversion of sample nitrite to $\mathrm{N}_{2} \mathrm{O}$ in a buffered sodium azide solution [64, 65]. A 1:1 mixture of $2 \mathrm{~mol} \mathrm{~L}^{-1}$ sodium azide and $20 \%$ glacial acetic acid was added to each sample in a gastight and crimp-sealed $20 \mathrm{~mL}$ glass vial (Restek Corp., Bellefonte, PA). Each sample received $10 \%$ azide reagent by volume, and was allowed to react for $1 \mathrm{~h}$ at room temperature. Samples were then neutralized with $0.1 \mathrm{~mL}$ of $6 \mathrm{~mol} \mathrm{~L}^{-1}$ sodium hydroxide per milliliter of sample before introduction into the IRMS. An internally calibrated nitrite standard $(-1.7 \%$ ) was analyzed for every seven samples to account for instrument drift. Due to the low DIN concentrations in our samples, a known amount $(\sim 10 \mathrm{nmol})$ of $\mathrm{NO}_{2}^{-}$was added as a 'carrier' during processing in order to increase the final amount of $\mathrm{N}_{2} \mathrm{O}$ in each sample to least $10 \mathrm{nmol}$ and increase signal size and improve measurement fidelity. The isotopic $\delta^{15} \mathrm{~N}$ composition of this carrier was well characterized $(-1.7 \%$ o for the internal sodium nitrite standard), and all carrier additions were made gravimetrically to minimize errors. The analytical precision for $\delta^{15} \mathrm{~N}$ measurements using the denitrifier and azide methods are typically $0.3 \%$ or better.

Potential $\mathrm{N}_{2} \mathrm{O}$ and $\mathrm{N}_{2}$ production rates from each incubation were measured directly from the gastight serum bottle samples. $\mathrm{N}_{2}$ measurements were performed first by drawing $1 \mathrm{~mL}$ of the headspace into a Hamilton gastight syringe and injecting directly into an injection port on the IRMS prep system, which included chromatic separation of $\mathrm{O}_{2}$ and $\mathrm{Ar}$ from $\mathrm{N}_{2}$ (Mol Sieve $5 \AA$, 1/8" OD x $2 \mathrm{~m}$ ). Due to the substantial headspace of air in the serum bottles during filling, the detection limit of $\mathrm{N}_{2}$ production was $1 \mu \mathrm{mol} \mathrm{L}{ }^{-1} \mathrm{~d}^{-1}\left(40-200 \mathrm{nmol} \mathrm{cm}^{-2} \mathrm{~d}^{-1}\right)$. The same serum bottle was then analyzed for ${ }^{15} \mathrm{~N}-\mathrm{N}_{2} \mathrm{O}$ production by sparging with $\mathrm{He}$ at a rate of $100 \mathrm{~mL} \mathrm{~min}^{-1}$ for $15 \mathrm{~min}$ to quantitatively strip any $\mathrm{N}_{2} \mathrm{O}$ out of the sample. Each sample was also purged inline with a second vial ("daisy-chained") containing $\mathrm{N}_{2} \mathrm{O}$ produced by the sodium azide method from the internal nitrite standard to accumulate sufficient $\mathrm{N}_{2} \mathrm{O}$ to resolve on the IRMS. The liberated $\mathrm{N}_{2} \mathrm{O}$ was concentrated in a liquid nitrogen cryotrap before introduction to the IRMS. The detection limit for $\mathrm{N}_{2} \mathrm{O}$ production was $10 \mathrm{nmol} \mathrm{L}^{-1} \mathrm{~d}^{-1}$ for ${ }^{15} \mathrm{NO}_{2}^{-}$and ${ }^{15} \mathrm{NO}_{3}^{-}$additions and $2 \mathrm{nmol} \mathrm{L}^{-1} \mathrm{~d}^{-1}$ for ${ }^{15} \mathrm{NH}_{4}{ }^{+}$additions.

Potential rates were calculated based on the difference between the initial and final timepoint measurements. Coral surface areas were used to normalize initial rate measurements from each incubation to a rate per surface area of coral tissue:

$$
\mathrm{R}^{\prime}=\mathrm{V} \times \frac{\mathrm{R}_{\mathrm{C}}-\mathrm{R}_{\mathrm{SW}}}{\mathrm{SA}},
$$

where $R^{\prime}$ is the surface area normalized transformation rate attributable to coral-associated nitrogen metabolism. Normalization by surface area $(S A)$ is important because it most clearly accounts for the quantity of microbial habitats within coral mucus and tissue. As all corals were incubated in reef seawater of volume $V$, potential rates from coral incubations $\left(R_{C}\right)$ were assumed to be a combination of both coral and seawater transformation rates $\left(R_{S W}\right)$. Thus, the rates from seawater-only incubations (generally an order of magnitude lower than the coral-associated rates) were subtracted in order to isolate the nitrogen cycling potential of direct coral associates. The volume was determined as the size of the incubation vessel correcting for the displacement by the coral fragment(s), but the coral volume accounted for generally $\lesssim 1 \%$ of the total chamber.

\section{Isolation and identification of anaerobic nitrate reducers}

Separate from the rate experiments, mucus and tissue samples from four healthy coral colonies-Montastraea 
cavernosa, O. faveolata, $P$. astreoides, and D. labyrinthiformis-were collected at site 4 (one of the sites sourced for the $O$. faveolata incubations), and inoculated shipboard on marine broth agar plates amended with $500 \mu \mathrm{mol} \mathrm{L}{ }^{-1}$ nitrate. Inoculated plates were incubated in the dark at $\sim 22{ }^{\circ} \mathrm{C}$ in a BD GasPak EZ container system (Becton, Dickinson and Company, Franklin Lakes, NJ) with five oxygen-scrubbing sachets. The anaerobic indicator showed that anoxic conditions were established after less than one day. Colonies were picked after approximately three weeks, re-plated, and regrown anaerobically on marine agar 2216 plates. Any plates with uniform colony growth were picked, transferred to liquid media for a final growth, and cryopreserved in $25 \%$ glycerol. Some plates with no growth after a week were stored at $4{ }^{\circ} \mathrm{C}$. After a year, some preserved plates had visible growth. These colonies, all Psychrobacter spp., were isolated using the same processing protocols. Cryopreserved isolates in glycerol were re-streaked in 2216 media amended with $10 \mathrm{mmol} \mathrm{L}^{-1}$ nitrate and incubated at $37^{\circ} \mathrm{C}$ in anaerobic conditions until colony growth was visible to confirm viability. Colonies were then picked and grown in liquid 2216 media anaerobically for DNA extraction. This process resulted in the growth of 29 isolation targets.

\section{Phenotypic assay for nitrogen oxide reduction ability}

A phenotypic assay was developed to verify the capability of the isolates to reduce nitrate and/or nitrite. Deep 96well plates were flushed for 15 minutes with nitrogen gas in a BD GasPak EZ container system and allowed to degas with oxygen-scrubbing sachets for two days. After degassing of the plastic plates, $1.880 \mathrm{~mL}$ of $\mathrm{N}_{2}$-equilibrated marine broth 2216 liquid media was added to each well. Preserved isolates were revived 24 hours prior to the experiments by inoculating in anoxic liquid media. Assays with nitrate or nitrite were conducted, with each well receiving a final concentration of one of the compounds of $50 \mu \mathrm{mol} \mathrm{L} \mathrm{L}^{-1}$. Subsequently, $20 \mu \mathrm{L}$ of previously revived isolate stock was amended to triplicate wells. Multiple plates were constructed in order to take three sacrificial timepoints for nitrite and four sacrificial timepoints for nitrate at different times. After inoculation, plates were stored in individual plastic bags with oxygenscrubbing catalysts and incubated at $30{ }^{\circ} \mathrm{C}$ under anaerobic conditions. Nitrite was measured on sacrificed plates via the Griess reaction [58] to visually determine if nitrate was consumed to produce nitrite and if nitrite was completely metabolized. For treatments with nitrate, the timepoints were: $4,8,24$, and 48 hours after inoculation; for nitrite treatments, the timepoints were: 24,48 , and 144 hours after inoculation.

\section{DNA extraction and 16S rRNA identification}

Bacterial isolates were grown aerobically in $50 \mathrm{~mL}$ of marine broth 2216 liquid culture overnight and centrifuged $(10,000 \times \mathrm{g})$ for 10 minutes. Afterwards, DNA from the cell pellet was extracted following the DNeasy Powerlyzer Microbial Kit protocol (Qiagen, Hilden, Germany). DNA quantity and purity were determined with a NanoDrop UV/ vis spectrophotometer (NanoDrop Technologies, Wilmington, DE). The small subunit ribosomal RNA gene was amplified with Quick-Load Taq 2X Master Mix (New England BioLabs, Ipswich, MA) using universal bacterial 8 F/1492 R primers and sent to Eton Bioscience for Sanger DNA sequencing using primers $8 \mathrm{~F}$ and $907 \mathrm{R}$. From the combined 16S sequencing and phenotypic assay results, the isolation targets were culled to 15 potential unique organisms for whole genome sequencing.

\section{Whole genome sequencing, genome assembly, and annotation}

Isolate DNA was purified and submitted to the BioMicro Center at the Massachusetts Institute of Technology for Whole Genome Sequencing (WGS). Library preparation for Illumina sequencing was done using the ligation based NEBNext Ultra II kit (New England BioLabs, Ipswich, MA). Samples were sequenced using paired-end MiSeq sequencing (V3 kit providing $300 \mathrm{bp}$ forward and $300 \mathrm{bp}$ reverse reads) (Illumina Inc., San Diego, CA). Genome assembly was accomplished by using the following pipeline: Trimmomatic [66] was used to clip ends of the Illumina adapters from the raw reads with the following parameter set: Illuminaclip: TruSeq3-PE-2.fa:2:20:10, Leading: 3, Trailing: 3, SlidingWindow: 10:20, Minlen: 36. Bayeshammer (part of the SPAdes package) [67] was used for error correcting and clustering. After error-correction of low-quality reads, a rough assembly and annotation was completed using MG-RAST [68] to compare with the identities obtained previously from 16S rRNA gene amplification. MegaHit [69] was used to assemble the genome, MaxBin [70] binned the assembled genomes and assigned operational taxonomic units (OTUs), and CheckM [71] was used to assesses genome quality, estimate completeness and provide genetic identification from marker genes (these are the reported identities). Annotation of the assembled genomes was done with the program PROKKA [72]. Genomes are available from the NCBI Genbank database, accession number PRJNA646503.

Organisms were characterized by the presence or absence of identified nitrate reductase (nar and nap), denitrifier nitrite, nitric oxide, and nitrous oxide reductases (nir, nor, and nos, respectively), and dissimilatory nitrite reductase to ammonium (nrf) genes. In short, genetic capacity was 
identified using HMMR v. 3.3 [73]. Hidden Markov Models (HMM) for narG, napA, nirS, nirK, norB, norC, $n o s Z$, and $n r f B$ were obtained from the TIGRFAMs resource maintained by the J. Craig Venter Institute.

\section{Results}

\section{Shipboard ammonium oxidation and nitrate reduction rates}

Inorganic nitrogen concentrations were low throughout the sites, with ammonium and nitrate each $<0.5 \mu \mathrm{mol} \mathrm{L}^{-1}$ and nitrite $\leq 0.06 \mu \mathrm{mol} \mathrm{L}^{-1}$ (Fig. 2). Coral cover at the sampling sites ranged from 11 to $35 \%$ (Fig. 2). At each site, the chosen species was sampled according to availability and abundance to minimize impact of destructive sampling. Overall, coral cover was higher at these sites $(25 \%$ on average) as compared with much of the Caribbean (currently estimated at 10-16\%) [52, 74]. Separate shipboard nitrogen tracer experiments with $P$. astreoides, $P$. porites, $D$. labyrinthiformis, A. palmata, and $O$. faveolata showed that coral-associated nitrate reduction to nitrite were detected in all coral species, and ammonium oxidation was detected in all species except A. palmata (Fig. 3, Supplementary Table 2). Coral-associated potential rates were calculated by subtracting the rate from the seawater-only incubation and normalizing to the surface area of the coral fragment incubated. The seawater rates (no coral fragment) were generally an order of magnitude slower than the coralassociated rates. Measured coral-associated rates of nitrate reduction, a suboxic reductive process, (generally $>1 \mathrm{nmol}$ of $\mathrm{N} \mathrm{cm}^{-2} \mathrm{~d}^{-1}$ ) were greatly in excess of ammonium

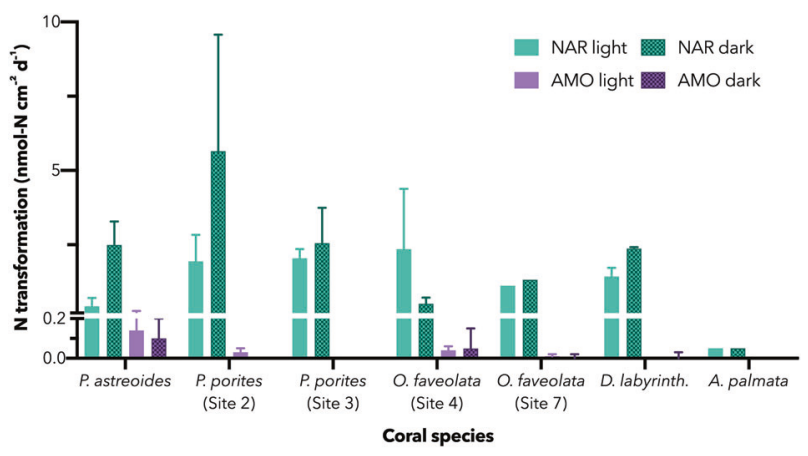

Fig. 3 Coral-associated rates of nitrogen metabolism. Duplicate rates of nitrate reduction (green, NAR) and ammonium oxidation (purple, AMO) were detected in association with multiple coral species ( $n=2$ per experiment and light treatment). These rates tended to be higher when incubated in full darkness (hashed bars) compared to diurnally varying light conditions (solid bars). Rates of ammonium oxidation tended to be an order of magnitude slower than nitrate oxidation. Coral-associated rates were determined by subtracting the rates from seawater controls $(n=2$ per light treatment). Error bars denote the range of measurements. oxidation, an oxidative process $\left(<0.2 \mathrm{nmol}\right.$ of $\left.\mathrm{N} \mathrm{cm}^{-2} \mathrm{~d}^{-1}\right)$. Moreover, whereas nitrate reduction rates were concentrated within the coral-amended incubations ( $t$-test, $p=$ $0.002)$, the ammonium oxidation rates were indistinguishable between coral-amended and seawater-only incubations $(t$-test, $p=0.87)$. Indeed, across all species sampled, ammonium oxidation rates displayed no coherent trend with either underlying nutrient concentrations, reef health as determined by coral coverage, host species, or light treatment.

Potential nitrate reduction rates were much faster than those of ammonium oxidation, changing the total seawater within an incubation chamber by up to $150 \mathrm{nmol} \mathrm{L}^{-1} \mathrm{~d}^{-1}$. The seawater-only (no coral) nitrate reduction rates accounted for only $2.8 \pm 1.0 \%$ (standard error, se) of the observed coral-associated rates. Thus, the vast majority of this high nitrate reduction rate was associated with the corals directly rather than by planktonic organisms subsisting in the bulk seawater. Potential nitrate reduction rates were further consistent across all species sampled with the exception of A. palmata, where nitrate reduction rates were measured to be just $0.05 \mathrm{nmol} \mathrm{cm}{ }^{-2} \mathrm{~d}^{-1}$. Nitrate reduction rates further show a dependence on light levels, with the dark incubations fostering higher rates than those undergoing natural diel light conditions. Pointedly, the dark incubations showed $2.00 \pm 0.52$ (se) fold higher nitrate reduction rates than their diurnal counterparts.

\section{Nitrous oxide production rates from multiple tracers}

We were unable to quantify denitrification and anammox rates to dinitrogen gas due to experimental limitations $\left({ }^{29} \mathrm{~N}_{2}\right.$ production below detection, not shown), but the potential rates of these processes could be constrained to $<40-200 \mathrm{nmol} \mathrm{cm}^{-2} \mathrm{~d}^{-1}$ based on the range of surface areas, or less than $1 \mu \mathrm{mol} \mathrm{L} \mathrm{L}^{-1} \mathrm{~d}^{-1}$ within the water. This does not mean that these metabolisms were absent, as the other transformation rates (including $\mathrm{N}_{2} \mathrm{O}$ production) were well below this threshold $\left(20-70 \mathrm{nmol} \mathrm{L}^{-1} \mathrm{~d}^{-1}\right.$ for nitrate reduction and $10-80 \mathrm{nmol} \mathrm{L}^{-1} \mathrm{~d}^{-1}$ for $\mathrm{N}_{2} \mathrm{O}$ production). By not purging the ample $\mathrm{N}_{2}$-background from our incubation vessels [75], our experimental design did not allow for the detection of ${ }^{15} \mathrm{~N}-\mathrm{N}_{2}$ production.

Production of ${ }^{15} \mathrm{~N}-\mathrm{N}_{2} \mathrm{O}$ was broadly detected from incubations inoculated with ${ }^{15} \mathrm{NO}_{3}^{-}$and ${ }^{15} \mathrm{NO}_{2}^{-}$(Fig. 4, Supplementary Table 3), but not generally from those inoculated with ${ }^{15} \mathrm{NH}_{4}{ }^{+}$. The exception was $D$. labyrinthiformis which produced measurable but small amounts of $\mathrm{N}_{2} \mathrm{O}$ from ammonium. When detected, Porites spp. generated $\mathrm{N}_{2} \mathrm{O}$ from $\mathrm{NO}_{3}{ }^{-}$and $\mathrm{NO}_{2}{ }^{-}$at rates averaging 0.37 $\pm 0.06(\mathrm{se}) \mathrm{nmol} \mathrm{L}^{-1} \mathrm{~d}^{-1}$ for the three incubations. Meanwhile, O. faveolata averaged $0.62 \pm 0.15 \mathrm{nmol} \mathrm{L}^{-1} \mathrm{~d}^{-1}$ across its two incubations. Despite only sampling 


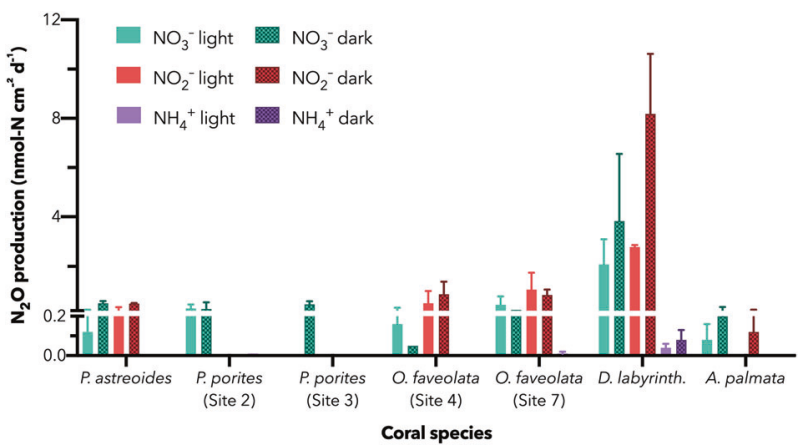

Fig. 4 Rates of $\mathrm{N}_{2} \mathrm{O}$ production from multiple metabolic routes. Duplicate $\mathrm{N}_{2} \mathrm{O}$ production rates are determined from nitrate (green), nitrite (red), and ammonium (purple) sources. The rates of production via reductive denitrifying processes, i.e., nitrate and nitrite reduction far exceed the rates from ammonium-based nitrifier denitrification. Error bars denote the range of measurements. D. labyrinthiformis harbored the fastest rates of denitrification, followed by $O$. faveolata. The Porites spp. and A. palmata indicated low but detectable rates on order of $0.2 \mathrm{nmol} \mathrm{cm}^{-2} \mathrm{~d}^{-1}$. Production of $\mathrm{N}_{2} \mathrm{O}$ from ammonium was only observed for $D$. labyrinthiformis, and at rates 20 and 40 times slower than for nitrate and nitrite reduction, respectively. Dark incubations (hashed bars) were generally faster than those under diurnally varying light (solid bars).

D. labyrinthiformis and A. palmata from one site each, their observed $\mathrm{N}_{2} \mathrm{O}$ production rates were consistent from $\mathrm{NO}_{2}{ }^{-}$ and $\mathrm{NO}_{3}^{-}$for each species, generating $4.2 \pm 1.1$ and $0.20 \pm$ $0.06 \mathrm{nmol} \mathrm{L}^{-1} \mathrm{~d}^{-1} \mathrm{~N}_{2} \mathrm{O}$, respectively. Due to the trace nature of $\mathrm{N}_{2} \mathrm{O}$ relative to $\mathrm{N}_{2}$ gas, the quantification of its production had a much lower limit of detection.

Strikingly, a similar enhancement of potential rates in the dark incubation as seen for $\mathrm{NO}_{3}^{-}$reduction was observed for $\mathrm{N}_{2} \mathrm{O}$ production via denitrifying metabolisms $\left(\mathrm{NO}_{2}{ }^{-}\right.$and $\mathrm{NO}_{3}^{-}$-derived pathways). The dark incubation rates averaged $1.7 \pm 0.4\left({ }^{15} \mathrm{NO}_{3}^{-}\right.$addition $)$and $2.0 \pm 0.3\left({ }^{15} \mathrm{NO}_{2}^{-}\right.$ addition) fold higher than their corresponding diurnally varying light experiments. This effect is especially pronounced for $D$. labyrinthiformis (Fig. 4). D. labyrinthiformis displays not only reproducible enhancement of $\mathrm{N}_{2} \mathrm{O}$ production from both $\mathrm{NO}_{2}{ }^{-}$and $\mathrm{NO}_{3}{ }^{-}$in the dark, these rates are within the margin of error of each other for both light and dark treatments (Fig. 5), indicating quantitative conversion of $\mathrm{NO}_{3}^{-}$to $\mathrm{NO}_{2}^{-}$to $\mathrm{N}_{2} \mathrm{O}$.

\section{Isolation and phenotyping of anaerobic nitrate reducing coral symbionts}

From the four coral species surveyed, we obtained 15 nitrate reducing bacterial isolates comprising five genus-level identities, all from the phylum Proteobacteria (Table 1). Of the organisms identified, Marinobacter spp. were found associated with $M$. cavernosa, $O$. faveolata, and $P$. astreoides, and in all cases were denitrifiers with the full complement of denitrification genes per our HMM searches.

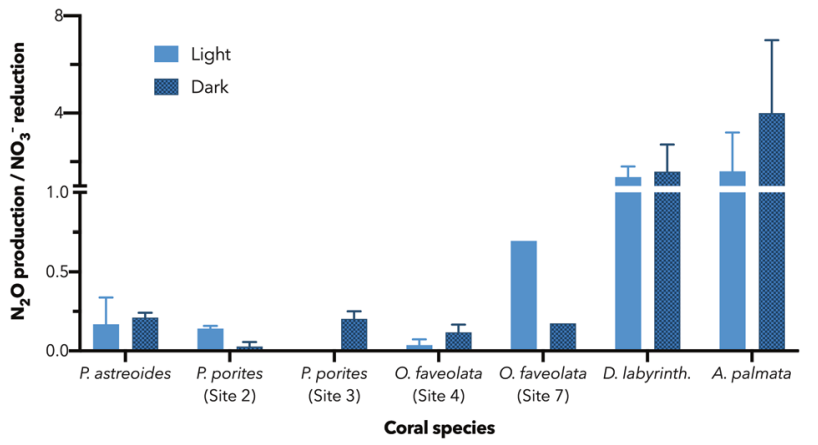

Fig. 5 Ratios of $\mathrm{N}_{2} \mathrm{O}$ production to $\mathrm{NO}_{3}{ }^{-}$reduction. A ratio of unity (1.0) indicates the equal reduction of nitrate to nitrite to $\mathrm{N}_{2} \mathrm{O}$, implying coupled reactions. Within the margin of error, D. labyrinthiformis and A. palmata indicate this occurrence, although $D$. labyrinthiformis displays much faster rates than A. palmata. Ratios less than one imply likely recycling of nitrogen, either via uptake or nitrification. Error bars denote range of duplicate measurements except in the case of $O$. faveolata (Site 7), where one replicate was lost.

Vibrio harveyi was found in association with each coral species, and in all cases had the ability to reduce nitrate to ammonium (DNRA). Pseudoalteromonas spp., Psychrobacter spp., and Vibrio sp. were found as well and each isolate was able to reduce nitrate to nitrite. Yet of these species, only the bacteria associated with $P$. astreoides were able to reduce nitrite via the phenotypic assay. Of the organisms isolated, each was able to consume nitrate and generate nitrite, and only the Pseudoalteromonas sp. and Psychrobacter spp. associated with D. labyrinthiformis and M. cavernosa were negative for nitrite reduction ability (Supplementary Fig. 3). Of the isolates obtained, $80 \%$ contained membrane-bound nitrate reductase narG, $60 \%$ contained periplasmic nitrate reductase napA, and $43 \%$ had both. Moreover, the only occurrences of nitrite (nirS or $n i r K$ ) and nitric oxide reductase (nor $B C$ ) were found in association with each other, and only for Marinobacter spp. In most cases, the results from the phenotypic assay agreed with the genome annotations made through targeted HMM analyses.

\section{Discussion}

These experiments reveal new evidence for anaerobic nitrogen cycling on reefs, which is driven by microorganisms within the coral holobiont. Occurrence of anaerobic processes in oxygenated bulk systems is potentially unexpected but not surprising. Numerous examples of the existence of micro-anaerobic sites exist in nature, from cyanobacterial and algal aggregates $[76,77]$ to marine snow particles [78] to sediments [79]. The governing principle in all of these systems is the same: biological oxygen consumption outpaces physical aeration via slow diffusion. 


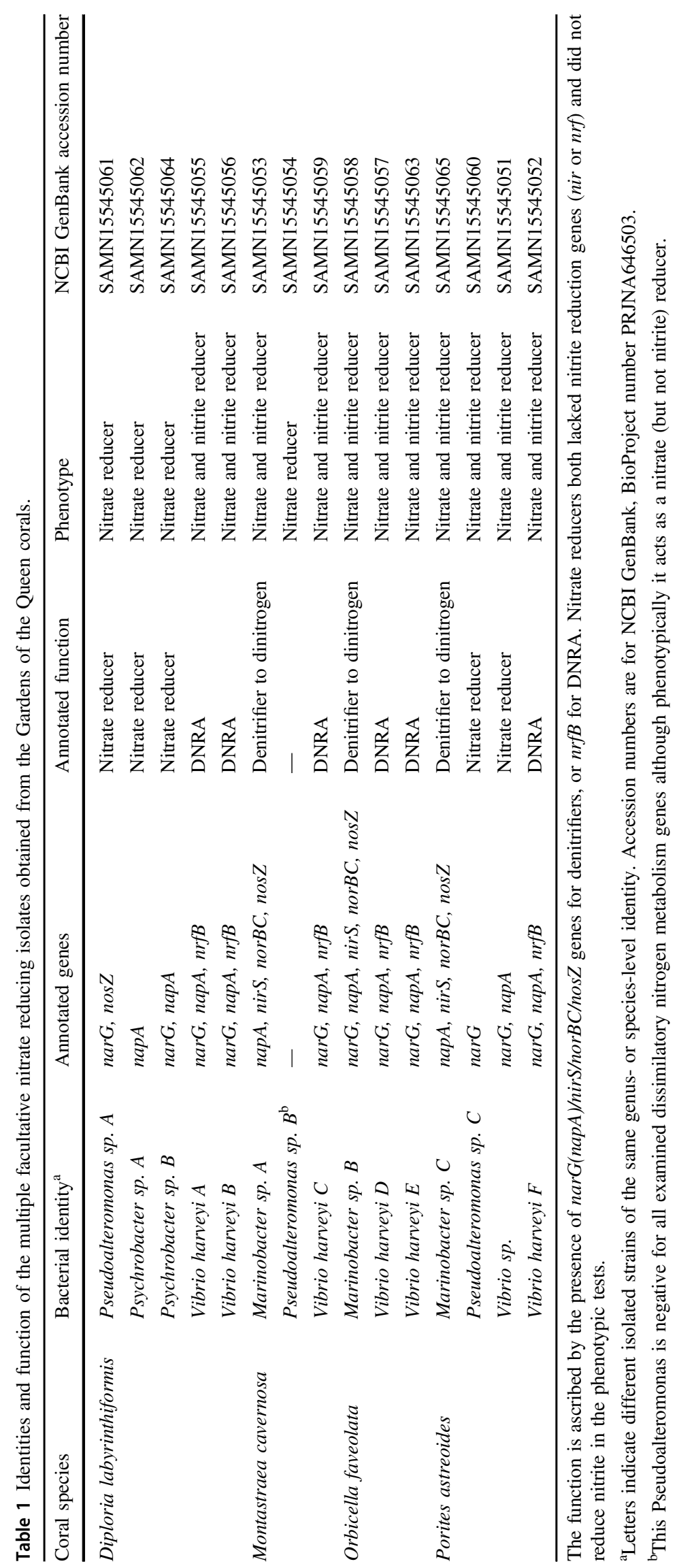




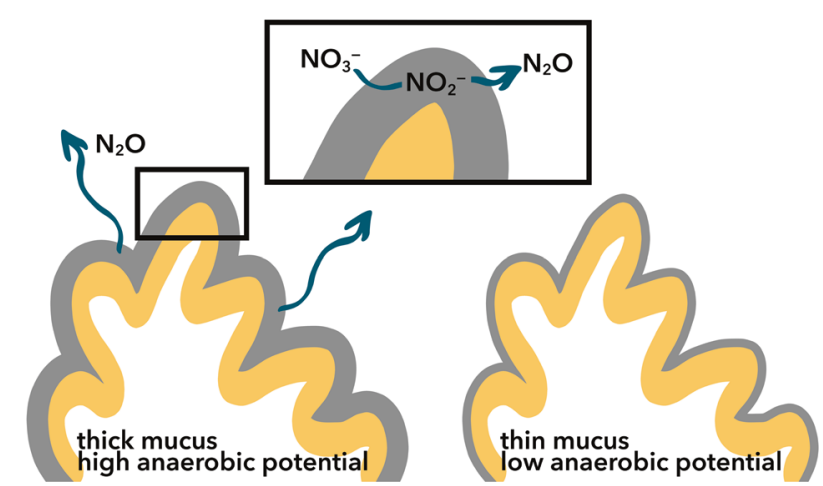

Fig. $6 \mathrm{~N}_{2} \mathrm{O}$ production schematic within corals. Thick mucus reduces oxygen supply and enables faster respiration, resulting in high anaerobic potential of associated microbes. These microbes must then reduce nitrate to nitrite and $\mathrm{N}_{2} \mathrm{O}$ (or ammonium) for energy. Thin mucus does not enable the same anaerobic metabolic rates as oxygen is not as sufficiently reduced.

Individual coral colonies are of a similar vein, especially given the mucus generating potential of the coral animal itself. This mucus acts not only to retard the diffusion of oxygen between bulk seawater but also as a carbon source, stimulating aerobic heterotrophy to actively draw down oxygen [40]. The thicker the mucus, the greater the potential for anaerobic processes to manifest even with bulk oxygen concentrations remaining too high to support denitrification within known oxygen constraints [80] (Fig. 6). As such, corals can host organisms that execute dissimilatory nitrate reduction, which can result in two pathways, each of which benefits the coral: (1) denitrification to $\mathrm{N}_{2} \mathrm{O}$ and $\mathrm{N}_{2}$ scrubs excess bio-available nitrogen that prevents macroalgal growth or (2) reduction to ammonium which permits more labile consumption of inorganic nitrogen for the coral and its symbionts [81].

The fact that ammonium oxidation rates were indistinguishable between coral-amended and seawater samples further supports the hypothesis that the mucus retards oxygenation and crafts a matrix less suitable for obligate aerobes. Indeed, the overall low rates of ammonium oxidation observed in the experiments were in line with expectations, whereby nitrification processes are inhibited by light through photo-stress [82] and from competition with ammonium assimilation by phototrophic organisms [83]. Low rates of ammonium oxidation in seawater around the corals may act to retard rates of nitrate reduction and denitrification in situ, as the supply of nitrate would be limited to flushing of the reef itself. However, nitrification by planktonic microbes may act to oxidize ammonium in seawater to nitrate, which is then supplied diffusionally to the coral associates. As such, the standing stock of nitrate concentrations can be maintained at the low $\left(<0.4 \mu \mathrm{mol} \mathrm{L}^{-1}\right)$ levels observed.

The dark experiments, compared to their diurnally varying light counterparts, also point to the prevalence of dissimilatory nitrate reduction metabolisms within the corals. The enhancement at low light of both nitrate reduction to nitrite and denitrifier production of $\mathrm{N}_{2} \mathrm{O}$ aligns with presumable periods of net respiration over photosynthesis among the coral-algae symbionts, conditions which would reduce oxygen and enable greater rates of anaerobic metabolisms. This is further confirmed by the observation that the amount of denitrification doubled for the dark experiments compared with an $\sim 12 / 12$ light/dark cycle in Jardines de la Reina. This agreement across the coral species sampled suggests anaerobic metabolisms are enhanced during the night-time only and relatively quiescent in daylight. This feature could be a result of oxygenic photosynthesis by the Symbiodinaceae algal symbionts reversibly inhibiting nitrate and nitrite reduction such that when oxygen production ceases due to insufficient light levels, nitrate and nitrite reduction become metabolically viable.

The benefits of dissimilatory nitrate and nitrite reduction within the coral holobiont are potentially substantial. Whereas these systems are severely limited by fixed nitrogen such that diazotrophs provide new nitrogen to the system, unchecked new nitrogen supplied by diazotrophy can lead to eutrophic conditions and the potential outcompetition of zooxanthellae by benthic or planktonic algae. Greater nutrient availability can also lead to the unhindered growth of Symbiodinaceae itself and a shift from mutualistic to parasitic interactions with its coral host [84]. As such, a delicate balance between the nitrogen sources of fixation and sinks of denitrification and uptake needs to be maintained for a healthy reef ecosystem. Denitrifiers act to remove excess nitrogen that may otherwise stimulate algal production, and dissimilatory reducers of nitrate to ammonium may provide more labile nitrogen to zooxanthellae, especially during the night when assimilatory phototrophic nitrate and nitrite reduction may be limited. Furthermore, a healthy reef supports numerous fish, which can excrete large quantities of ammonium in close proximity of coral colonies, at rates similar to nitrogen fixation, which can stimulate growth of both Porites and Acropora corals [85]. Algae can rapidly assimilate these dynamic ammonium pulses [86] if not in competition with the holobiont for limited nitrogen resources.

Because of the double-edged nature of nitrogen nutrients, one can anticipate that a healthy reef would be one with a large diversity not just in organisms but also in metabolic pathways that act to maintain tight regulation of nutrient availability. Incredibly, the nitrate reduction rates observed here are on par with those observed in the anoxic marine oxygen minimum zones that are characterized by their hosting the denitrification metabolism [87, 88]. Indeed, evidence is emerging that denitrification is also important among analogous Red Sea corals [89, 90] The ability of natural coral-associated communities to reduce nitrate and 
denitrify is especially important to buffer against negative impacts in the Anthropocene, when increasing nitrogen supply can increase severity of coral disease [3, 4] and bleaching altogether [91].

The identification of the nitrate-reducing and denitrifying abilities of the coral holobiont allows a fuller picture of the nitrogen cycle associated with corals to be developed. Coral systems thrive despite the low nutrient availability because of the presence of diazotrophs in association with the corals, in the benthos, and among planktonic cells [16], but too much nitrogen fixation could cause macroalgae to flourish. Nitrogen fixation rates have been quantified among scleractinian corals to be highly species-specific, ranging from undetectable to $\sim 2 \mathrm{nmol} \mathrm{cm}^{-2} \mathrm{~d}^{-1}$ in some [92,93], to greater than $100 \mathrm{nmol} \mathrm{cm}^{-2} \mathrm{~d}^{-1}[16,94]$ in others. The high variability in diazotrophy measurements indicates that the nitrate reduction and denitrification rates measured here may be significant contributors in the overall nitrogen balance for certain corals and at specific times. To that end, the ability of denitrifiers to remove excess nitrogen from the system can help maintain a healthy reef, otherwise imbalanced by the input of nitrogen fixation (or external nitrogen loading) and the output via nitrogen burial or advective transport. It can be hypothesized that without denitrifiers, the coral-Symbiodinaceae partnership could be outcompeted by other algae due to excess fixed nitrogen availability on the local scale, although importantly reef sediments too host denitrifying processes. However, denitrification is not the only dissimilatory nitrate consumption process. Dissimilatory reducers of nitrate to ammonium too were isolated from these corals, although we did not quantify rates of this process in situ. These organisms can potentially form a unique partnership with the coral and endosymbiotic algae too, in providing them a more readily labile reduced nitrogen source for assimilatory metabolisms. It has been shown for multiple scleractinian corals that ammonium is the preferred nitrogen substrate [95, 96]. Moreover, DNRA organisms may have the ability to detoxify nitrite, releasing $\mathrm{N}_{2} \mathrm{O}$ as a product. The results here point to the need to revisit the full complexity of the nitrogen metabolisms active among microbial coral associates, and the roles each has in maintaining a productive reef environment.

In summary, diazotrophy and nitrogen assimilation have understandably been the focus of many coral reef studies to date. However, as shown with this study, a diversity of metabolisms operating in concert with nitrogen fixation and nutrient uptake exists. The direct measurements of $\mathrm{N}_{2} \mathrm{O}$ from multiple ${ }^{15} \mathrm{~N}$ tracers are to our knowledge the first of their kind applied to tropical reef systems. The production of ${ }^{15} \mathrm{~N}_{2} \mathrm{O}$ from the ${ }^{15} \mathrm{NO}_{3}{ }^{-}$and ${ }^{15} \mathrm{NO}_{2}^{-}$tracer experiments observed here provides strong evidence of fixed $\mathrm{N}$ loss from the system, from canonical and/or nitrifier denitrification, or detoxification. With nutrient pulses from anthropogenic effluent or ammonia excretion by fish [97], the importance of dissimilatory pathways could help maintain an overall balance $[17,98]$.

Coral health hinges on the dynamic relationship among members of the holobiont; microbial nitrogen cycling may play a central role in the maintenance of the seawater and boundary layer chemistry underlying the stability of the coral holobiont. The network of microbial nitrogen metabolisms is an especially important consideration in modern reefs, as anthropogenic nutrients, warmer temperatures, and decreased $\mathrm{pH}$ can alter the nitrogen speciation of the bulk water and the energetic yield of multiple metabolisms. These corals, like Porites and Diploria, form the basis of paleo-proxies used to understand previous climate and ocean states, and thus the isotopic fractionation involved with these dissimilatory metabolisms may need to be considered [99, 100]. Three lifestyles of anaerobic nitrogen bacteria were found here, nitrate-only reducers, denitrifiers, and DNRA organisms. The net effect this community has on overall nutrient cycling and biogeochemistry depends on the relative abundance and activities of these important microorganisms. Resolving this balance will rely on future measurements that monitor oxygen, preferably at the scale of the coral polyp itself, increase replication across coral species, and simultaneously measure rates of nitrogen fixation and denitrification.

Acknowledgements We thank the captain and crew of the MV Alucia for their assistance in sampling, and the Dalio Foundation for cruise funding. We graciously acknowledge the assistance of Net Charoenpong, Jen Karolewski, Ashlee Lillis, Rachel Soble, and Steven Smriga in producing this work and the guidance of Alyson Santoro in experimental design. Research was conducted in the Gardens of the Queen, Cuba in accordance with the requirements of the Republic of Cuba, conducted under permit NV2370 and NV2568 issued by the Ministerio de Relaciones Exteriores. We gratefully acknowledge funding for this research by MIT Sea Grant award \#2018-DOH-49LEV, Simons Foundation award \#622065, and MIT ESI seed funding to ARB, the MIT Montrym, Ferry, and mTerra Seed Grant Funds, and the generous contributions by Dr Bruce L. Heflinger.

Author contributions The project was conceived and designed by ARB with substantial input by AA. Shipboard experiments were conducted by ARB and TT, with assistance by LW, MA, and AA. Isotope mass spectrometry was performed by TT and SDW. Shipboard cultivation was completed by ARB and MVIR. Isolation of organisms was done by DD and SLS. Phenotyping, characterization, and whole genome analysis conducted by DD. ARB and TT wrote the paper with input from AA. All authors reviewed, edited, and contributed to the final version.

\section{Compliance with ethical standards}

Conflict of interest The authors declare that they have no conflict of interest. 
Publisher's note Springer Nature remains neutral with regard to jurisdictional claims in published maps and institutional affiliations.

Open Access This article is licensed under a Creative Commons Attribution 4.0 International License, which permits use, sharing, adaptation, distribution and reproduction in any medium or format, as long as you give appropriate credit to the original author(s) and the source, provide a link to the Creative Commons license, and indicate if changes were made. The images or other third party material in this article are included in the article's Creative Commons license, unless indicated otherwise in a credit line to the material. If material is not included in the article's Creative Commons license and your intended use is not permitted by statutory regulation or exceeds the permitted use, you will need to obtain permission directly from the copyright holder. To view a copy of this license, visit http://creativecommons. org/licenses/by/4.0/.

\section{References}

1. Spalding MD, Grenfell AM. New estimates of global and regional coral reef areas. Coral Reefs. 1997;16:225-30.

2. Kleypas J, Menez L, McManus J. Environmental limits to coral reef development: where do we draw. Methods. 1999;159:146-59.

3. Bruno JF, Petes LE, Drew Harvell C, Hettinger A. Nutrient enrichment can increase the severity of coral diseases. Ecol Lett. 2003;6:1056-61.

4. Vega Thurber RL, Burkepile DE, Fuchs C, Shantz AA, McMinds R, Zaneveld JR. Chronic nutrient enrichment increases prevalence and severity of coral disease and bleaching. Glob Chang Biol. 2014;20:544-54.

5. Shantz AA, Burkepile DE. Context-dependent effects of nutrient loading on the coral-algal mutualism. Ecology. 2014;95: 1995-2005.

6. Hoegh-Guldberg O, Poloczanska ES, Skirving W, Dove S. Coral Reef ecosystems under climate change and ocean acidification. Front Mar Sci. 2017;4:158.

7. Rohwer F, Seguritan V, Azam F, Knowlton N. Diversity and distribution of coral-associated bacteria. Mar Ecol Prog Ser. 2002;243:1-10.

8. Falkowski PG, Fenchel T, Delong EF. The microbial engines that drive Earth's biogeochemical cycles. Science. 2008;320: 1034-9.

9. Bourne DG, Morrow KM, Webster NS. Insights into the Coral microbiome: underpinning the health and resilience of reef ecosystems. Annu Rev Microbiol. 2016;70:317-40.

10. Darwin C. The structure and distribution of coral reefs, 3rd edn. D. Appleton \& Company: New York, NY, USA, 1889.

11. Sammarco PW, Risk MJ, Schwarcz HP, Heikoop JM. Crosscontinental shelf trends in coral $\delta_{15} \mathrm{~N}$ on the great barrier reef: further consideration of the reef nutrient paradox. Mar Ecol Prog Ser. 1999;180:131-8.

12. Fiore CL, Jarett JK, Olson ND, Lesser MP. Nitrogen fixation and nitrogen transformations in marine symbioses. Trends Microbiol. 2010;18:455-63.

13. Wegley L, Edwards R, Rodriguez-Brito B, Liu H, Rohwer F. Metagenomic analysis of the microbial community associated with the coral Porites astreoides. Environ Microbiol. 2007;9:2707-19.

14. Lema KA, Willis BL, Bourneb DG. Corals form characteristic associations with symbiotic nitrogen-fixing bacteria. Appl Environ Microbiol. 2012;78:3136-44.

15. Yang S, Sun W, Zhang F, Li Z. Phylogenetically diverse denitrifying and ammonia-oxidizing bacteria in corals Alcyonium gracillimum and Tubastraea coccinea. Mar Biotechnol. 2013;15:540-51.
16. Wiebe WJ, Johannes RE, Webb KL. Nitrogen fixation in a coral reef community. Science. 1975;188:257-9.

17. Rädecker N, Pogoreutz C, Voolstra CR, Wiedenmann J, Wild C. Nitrogen cycling in corals: the key to understanding holobiont functioning? Trends Microbiol. 2015;23:490-7.

18. van Oevelen D, Vermeij MJA, Middelburg JJ, de Goeij JM, Osinga R, de Goeij AFPM, et al. Surviving in a marine desert: the sponge loop retains resources within coral reefs. Science. 2013;342:108-10.

19. Price NM, Andersen LF, Morel FMM. Iron and nitrogen nutrition of equatorial Pacific plankton. Deep Sea Res Part A, Oceanogr Res Pap. 1991;38:1361-78.

20. Eppley RW, Renger EH. Nitrogen assimilation of an oceanic diatom in nitrogen-limited continuous culture. J Phycol. 1974;10:15-23.

21. Eugster O, Gruber N. A probabilistic estimate of global marine $\mathrm{N}$-fixation and denitrification. Global Biogeochem Cycles. 2012;26:GB4013.

22. Zehr JP. Nitrogen fixation by marine cyanobacteria. Trends Microbiol. 2011;19:162-73.

23. Codispoti LA, Christensen JP. Nitrification, denitrification and nitrous oxide cycling in the eastern tropical South Pacific ocean. Mar Chem. 1985;16:277-300.

24. Capone DG, Dunham SE, Horrigan SG, Duguay LE. Microbial nitrogen transformations in unconsolidated coral reef sediments. Mar Ecol Prog Ser. 1992;80:75-88.

25. Zumft WG. Cell biology and molecular basis of denitrification. Microbiol Mol Biol Rev. 1997;61:533-616.

26. Bonin P, Gilewicz M, Bertrand JC. Effects of oxygen on each step of denitrification on Pseudomonas nautica. Can J Microbiol. 1989;35:1061-4.

27. Hardison AK, Algar CK, Giblin AE, Rich JJ. Influence of organic carbon and nitrate loading on partitioning between dissimilatory nitrate reduction to ammonium (DNRA) and $\mathrm{N}_{2}$ production. Geochim Cosmochim Acta. 2015; 164:146-60.

28. Porubsky WP, Weston NB, Joye SB. Benthic metabolism and the fate of dissolved inorganic nitrogen in intertidal sediments. Estuar Coast Shelf Sci. 2009;83:392-402.

29. Lam P, Lavik G, Jensen MM, van de Vossenberg J, Schmid M, Woebken D, et al. Revising the nitrogen cycle in the Peruvian oxygen minimum zone. Proc Natl Acad Sci. 2009;106:4752-7.

30. Smethie WM. Nutrient regeneration and denitrification in low oxygen fjords. Deep Sea Res Part A, Oceanogr Res Pap. 1987;34:983-1006.

31. Strous M, van Gerven E, Huenen G, Jetten M. Effect of aerobic and microaerobic conditions on (Anammox) Sludge. Appl Environ Microbiol. 1997;63:2446-8.

32. Postgate JR. Biology nitrogen fixation: fundamentals. Philos Trans R Soc Lond B Biol Sci. 1982;296:375-85.

33. Wezernak CT, Gannon JJ. Oxygen-nitrogen relationships in autotrophic nitrification. Appl Microbiol. 1967;15:1211-4.

34. Sabaty M, Gans P, Vermglio A. Inhibition of nitrate reduction by light and oxygen in Rhodobacter sphaeroides forma sp. denitrificans. Arch Microbiol. 1993;159:153-9.

35. Körner H, Zumft WG. Expression of denitrification enzymes in response to the dissolved oxygen level and respiratory substrate in continuous culture of Pseudomonas stutzeri. Appl Environ Microbiol. 1989;55:1670-6.

36. Sournia A. Oxygen metabolism of a fringing reef in French Polynesia. Helgoländer Wissenschaftliche Meeresuntersuchungen. 1976;28:401-10.

37. Agostini S, Suzuki Y, Higuchi T, Casareto BE, Yoshinaga K, Nakano Y, et al. Biological and chemical characteristics of the coral gastric cavity. Coral Reefs. 2012;31:147-56. 
38. Shashar N, Cohen Y, Loya Y. Extreme diel fluctuations of oxygen in diffusive boundary layers surrounding stony corals. Biol Bull. 1993;185:455-61.

39. Guadayol Ò, Silbiger NJ, Donahue MJ, Thomas FIM. Patterns in temporal variability of temperature, oxygen and $\mathrm{pH}$ along an environmental gradient in a coral reef. PLoS ONE. 2014;9: e85213.

40. Wild C, Huettel M, Klueter A, Kremb SG, Rasheed MYM, Jørgensen BB. Coral mucus functions as an energy carrier and particle trap in the reef ecosystem. Nature. 2004;428:66-70.

41. McKew BA, Dumbrell AJ, Daud SD, Hepburn L, Thorpe E, Mogensen L, et al. Characterization of geographically distinct bacterial communities associated with coral mucus produced by Acropora spp. and Porites spp. Appl Environ Microbiol. 2012;78:5229-37.

42. Humphries AT, Ayvazian SG, Carey JC, Hancock BT, Grabbert $\mathrm{S}$, Cobb D, et al. Directly measured denitrification reveals oyster aquaculture and restored oyster reefs remove nitrogen at comparable high rates. Front Mar Sci. 2016;3:1-10.

43. Hoffmann F, Radax R, Woebken D, Holtappels M, Lavik G, Rapp HT, et al. Complex nitrogen cycling in the sponge Geodia barretti. Environ Microbiol. 2009;11:2228-43.

44. Siboni, Ben-Dov E, Sivan A, Kushmaro A. Global distribution and diversity of coral-associated Archaea and their possible role in the coral holobiont nitrogen cycle. Environ Microbiol. 2008;10:2979-90.

45. Middelburg JJ, Mueller CE, Veuger B, Larsson AI, Form A, Van Oevelen D. Discovery of symbiotic nitrogen fixation and chemoautotrophy in cold-water corals. Sci Rep. 2015;5:1-9.

46. Kiriakoulakis K, Fisher E, Wolff GA, Freiwald A, Grehan A, Roberts JM. Lipids and nitrogen isotopes of two deep-water corals from the North-East Atlantic: initial results and implications for their nutrition. In: Freiwald A, Roberts JM (eds). ColdWater Corals and Ecosystems. Springer: Berlin, Heidelberg, 2005, pp 715-29.

47. van Oevelen D, Duineveld GCA, Lavaleye MSS, Kutti T, Soetaert K. Trophic structure of cold-water coral communities revealed from the analysis of tissue isotopes and fatty acid composition. Mar Biol Res. 2018;14:287-306.

48. van den Beld IMJ, Bourillet J, Arnaud-Haond S, de Chambure L, Davies JS, Guillaumont B, et al. Cold-water coral habitats in submarine canyons of the Bay of Biscay. Front Mar Sci. 2017;4:118.

49. Fiore CL, Baker DM, Lesser MP. Nitrogen Biogeochemistry in the Caribbean Sponge, Xestospongia muta: a source or sink of dissolved inorganic nitrogen? PLoS ONE. 2013;8:1-11.

50. Hoffmann F, Larsen O, Thiel V, Rapp HT, Pape T, Michaelis W, et al. An anaerobic world in sponges. Geomicrobiol J. 2005;22:1-10.

51. Wafar M, Wafar S, David JJ. Nitrification in reef corals. Limnol Oceanogr 1990;35:725-30.

52. Weber L, González-Díaz P, Armenteros M, Ferrer VM, Bretos F, Bartels E, et al. Microbial signatures of protected and impacted Northern Caribbean reefs: changes from Cuba to the Florida Keys. Environ Microbiol. 2020;22:499-519.

53. Thampi VA, Anand M, Bauch CT. Socio-ecological dynamics of Caribbean coral reef ecosystems and conservation opinion propagation. Sci Rep. 2018;8:1-11.

54. Jackson J, Donovan M, Cramer K, Lam V. Status and trends of caribbean coral reefs: 1970-2012. Switzerland: Global Coral Reef Monitoring Network, IUCN, Gland; 2014.

55. Eakin CM, Morgan JA, Heron SF, Smith TB, Liu G, AlvarezFilip L, et al. Caribbean corals in crisis: record thermal stress, bleaching, and mortality in 2005. PLoS ONE. 2010;5:e13969.

56. Joyner JL, Sutherland KP, Kemp DW, Berry B, Griffin A, Porter $\mathrm{JW}$, et al. Systematic analysis of white pox disease in Acropora palmata of the Florida Keys and role of Serratia marcescens. Appl Environ Microbiol. 2015;81:4451-7.

57. Valdivia A, Cox CE, Bruno JF. Predatory fish depletion and recovery potential on Caribbean reefs. Sci Adv. 2017;3:1-12.

58. Strickland JDH, Parsons TR. A practical handbook of seawater analysis, 2nd edn. Fisheries Research Board of Canada: Ottawa, 1972.

59. Hydes D, Aoyama M, Aminot A, Bakker K, Becker S, Coverly $\mathrm{S}$, et al. Determination of dissolved nutrients $(\mathrm{N}, \mathrm{P}, \mathrm{Si})$ in seawater with high precision and inter-comparability using gassegmented continuous flow analysers. In: Hood EM, Sabine CL, Sloyan BM (eds). The GO-SHIP Repeat Hydrography Manual: A Collection of Expert Reports and Guidelines. IOCCP Report Number 14, ICPO Publication Series Number 134, 2010.

60. Barron MG, Vivian DN, Yee SH, Santavy DL. Methods to estimate solar radiation dosimetry in coral reefs using remote sensed, modeled, and in situ data. Environ Monit Assess. 2009;151:445-55.

61. Buesa RJ. Annual benthic irradiance levels at the Northwestern Cuban shelf. Reg Stud Mar Sci. 2020;33:100969.

62. Marsh J. Primary productivity of reef-building calcareous red algae. Ecol Soc Am. 1970;51:255-63.

63. Naumann MS, Niggl W, Laforsch C, Glaser C, Wild C. Coral surface area quantification-evaluation of established techniques by comparison with computer tomography. Coral Reefs. 2009;28:109-17.

64. McIlvin MR, Altabet MA. Chemical conversion of nitrate and nitrite to nitrous oxide for nitrogen and oxygen isotopic analysis in freshwater and seawater. Anal Chem. 2005;77:5589-95.

65. Tu Y, Fang Y, Liu D, Pan Y. Modifications to the azide method for nitrate isotope analysis. Rapid Commun Mass Spectrom. 2016;30:1213-22.

66. Bolger AM, Lohse M, Usadel B. Trimmomatic: a flexible trimmer for Illumina sequence data. Bioinformatics. 2014;30:2114-20.

67. Nikolenko SI, Korobeynikov AI, Alekseyev MA. BayesHammer: Bayesian clustering for error correction in single-cell sequencing. BMC Genom. 2013;14:S7.

68. Meyer F, Paarmann D, D'Souza M, Olson R, Glass E, Kubal M, et al. The metagenomics RAST server - a public resource for the automatic phylogenetic and functional analysis of metagenomes. BMC Bioinforma. 2008;9:386.

69. Li D, Liu CM, Luo R, Sadakane K, Lam TW. MEGAHIT: an ultra-fast single-node solution for large and complex metagenomics assembly via succinct de Bruijn graph. Bioinform. 2015;31:1674-6.

70. Wu Y-W, Simmons BA, Singer SW. MaxBin 2.0: an automated binning algorithm to recover genomes from multiple metagenomic datasets. Bioinformatics. 2016;32:605-7.

71. Parks DH, Imelfort M, Skennerton CT, Hugenholtz P, Tyson GW. CheckM: assessing the quality of microbial genomes recovered from isolates, single cells, and metagenomes. Genome Res. 2015;25:1043-55.

72. Seemann T. Prokka: rapid prokaryotic genome annotation. Bioinform. 2014;30:2068-9.

73. Eddy SR. Profile hidden Markov models. Bioinform. 1998;14:755-63.

74. Schutte VGW, Selig ER, Bruno JF. Regional spatio-temporal trends in Caribbean coral reef benthic communities. Mar Ecol Prog Ser. 2010;402:115-22.

75. Babbin AR, Buchwald C, Morel FMM, Wankel SD, Ward BB. Nitrite oxidation exceeds reduction and fixed nitrogen loss in anoxic Pacific waters. Mar Chem. 2020;224:103814.

76. Klawonn I, Bonaglia S, Brüchert V, Ploug H. Aerobic and anaerobic nitrogen transformation processes in $\mathrm{N}_{2}$-fixing cyanobacterial aggregates. ISME J. 2015;9:1456-66. 
77. Stief P, Kamp A, Thamdrup B, Glud RN. Anaerobic nitrogen turnover by sinking diatom aggregates at varying ambient oxygen levels. Front Microbiol. 2016;7:98.

78. Shanks AL, Reeder ML. Reducing microzones and sulfide production in marine snow. Mar Ecol Prog Ser. 1993;96:43-7.

79. Fennel K, Brady D, DiToro D, Fulweiler RW, Gardner WS, Giblin A, et al. Modeling denitrification in aquatic sediments. Biogeochemistry. 2009;93:159-78.

80. Dalsgaard T, Stewart FJ, Thamdrup B, De Brabandere L, Revsbech NP, Ulloa $\mathrm{O}$, et al. Oxygen at nanomolar levels reversibly suppresses process rates and gene expression in anammox and denitrification in the oxygen minimum zone off northern Chile. MBio. 2014;5:e01966.

81. Pernice M, Meibom A, Van Den Heuvel A, Kopp C, DomartCoulon I, Hoegh-Guldberg O, et al. A single-cell view of ammonium assimilation in coral-dinoflagellate symbiosis. ISME J. 2012;6:1314-24.

82. Hooper AB, Terry KR. Specific inhibitors of ammonia oxidation in Nitrosomonas. J Bacteriol. 1973;115:480-5.

83. Smith JM, Chavez FP, Francis CA. Ammonium uptake by phytoplankton regulates nitrification in the sunlit ocean. PLoS ONE. 2014;9:e108173-e108173.

84. Baker DM, Freeman CJ, Wong JCY, Fogel ML, Knowlton N. Climate change promotes parasitism in a coral symbiosis. ISME J. 2018;12:921-30.

85. Meyer JL, Schultz ET, Helfman GS. Fish schools: an asset to corals. Science. 1983;220:1047-9.

86. McCarthy JJ, Goldman JC. Nitrogenous nutrition of marine phytoplankton in nutrient-depleted waters. Science. 1979;203:670-2.

87. Kalvelage T, Lavik G, Lam P, Contreras S, Arteaga L, Löscher $\mathrm{CR}$, et al. Nitrogen cycling driven by organic matter export in the South Pacific oxygen minimum zone. Nat Geosci. 2013;6:228-34

88. Babbin AR, Peters BD, Mordy CW, Widner B, Casciotti KL, Ward BB. Multiple metabolisms constrain the anaerobic nitrite budget in the Eastern Tropical South Pacific. Global Biogeochem Cycles. 2017;31:258-71.
89. Tilstra A, El-Khaled YC, Roth F, Rädecker N, Pogoreutz C, Voolstra CR, et al. Denitrification aligns with $\mathrm{N}_{2}$ fixation in red sea corals. Sci Rep. 2019;9:19460.

90. El-Khaled Y, Roth F, Tilstra A, Rädecker N, Karcher D, Kürten $B$, et al. In situ eutrophication stimulates dinitrogen fixation, denitrification, and productivity in Red Sea coral reefs. Mar Ecol Prog Ser. 2020;645:55-66.

91. Donovan MK, Adam TC, Shantz AA, Speare KE, Munsterman KS, Rice MM, et al. Nitrogen pollution interacts with heat stress to increase coral bleaching across the seascape. Proc Natl Acad Sci USA. 2020;117:5351-7.

92. Grover R, Ferrier-Pagès C, Maguer J-F, Ezzat L, Fine M. Nitrogen fixation in the mucus of Red Sea corals. J Exp Biol. 2014;217:3962-3.

93. Pogoreutz C, Rädecker N, Cárdenas A, Gärdes A, Wild C, Voolstra CR. Nitrogen fixation aligns with nifH abundance and expression in two coral trophic functional groups. Front Microbiol. 2017;8:1187.

94. Shashar N, Cohen Y, Loya Y, Sar N. Nitrogen fixation (acetylene reduction) in stony corals: evidence for coral-bacteria interactions. Mar Ecol Prog Ser. 1994;111:259-64.

95. Domotor SL, D'Elia CF. Nutrient uptake kinetics and growth of zooxanthellae maintained in laboratory culture. Mar Biol. 1984;80:93-101.

96. Wilkerson FP, Trench RK. Uptake of dissolved inorganic nitrogen by the symbiotic clam Tridacna gigas and the coral Acropora sp. Mar Biol. 1986;93:237-46.

97. Randall DJ, Wright PA. Ammonia distribution and excretion in fish. Fish Physiol Biochem. 1987;3:107-20.

98. Burkepile DE, Allgeier JE, Shantz AA, Pritchard CE, Lemoine NP, Bhatti LH, et al. Nutrient supply from fishes facilitates macroalgae and suppresses corals in a Caribbean coral reef ecosystem. Sci Rep. 2013;3:19-21.

99. Ren H, Chen Y-C, Wang XT, Wong GTF, Cohen AL, DeCarlo $\mathrm{TM}$, et al. 21st-century rise in anthropogenic nitrogen deposition on a remote coral reef. Science. 2017;356:749-52.

100. Wang XT, Cohen AL, Luu V, Ren H, Su Z, Haug GH, et al. Natural forcing of the North Atlantic nitrogen cycle in the Anthropocene. Proc Natl Acad Sci USA. 2018;115:10606. 